УДК 811.161'42:070(045)

ББК 81.411-7

DOI: https://doi.org/10.17308/lic.2021.1/3232

\title{
ЛЕКСИЧЕСКИЕ ДОМИНАНТЫ КАК КОМПОНЕНТЫ ЦЕННОСТНОЙ МОДЕЛИ ОБЩЕСТВА
}

\author{
А. А. Биюмена \\ Минский государственный лингвистический университет

\section{LEXICAL DOMINANTS AS COMPONENTS OF THE SOCIETY VALUE MODEL}

\author{
A. A. Biyumena \\ Minsk State Linguistic University
}

\begin{abstract}
Аннотация: в статье рассматривается функционирование наименований лиц, относящихся к их трудовой деятельности, в печатном медиадискурсе советского периода. Данные номинации занимали значимое место в советских газетах и использовались как средство конструирования социальной идентичности граждан страны. Наиболее популярными среди них были существительные рабочий и колхозник/колхозница, указываюшие на «престижные» в Советском Союзе соииальные классы. Частотностью и разнообразием составляющих единиц отличались группы наименований конкретных рабочих и сельскохозяйственных специиальностей, в то время как названия профессий, требующих спещиального образования и высокой квалификачии, редко использовались в печатных изданиях советского времени. Специфичной для анализируемого исторического периода является группа обозначений лучших работников (ударник, передовик, новатор, стаханавец и т. п.). В контексте советского медиадискурса наименования лии, указывающие на их трудовую деятельность, реализовали оченочные, идеологические и статусные прагматические коннотации. В подавляющем большинстве материалов они актуализировали положительную оченочность и подчеркивали высокий статус и общественную значимость в СССР людей, занимаюшихся тяжелым физическим трудом. Выявлено, что ведущим типом идентичности в прессе советского периода выступала трудовая идентичность, а наименования лии по вовлеченности в трудовую деятельность функционировали в прессе как ключевые слова эпохи, ее лексические маркеры, идеологические клише и иенностные доминанты. Они использовались для стимулирования групповой сплоченности населения, повышения 8 общественном сознании ценности «человека труда», мобилизации граждан на самоотверженный труд и перевыполнение норм и заданий.
\end{abstract}

Ключевые слова: медиадискурс, пресса, идентичность, труд, идеология, имя существительное, номинация, оценка, коннотация.

\begin{abstract}
: the article examines functioning of the person names related to labor activity in the print media discourse of the Soviet period. Names of professions played a significant role in the texts of Soviet newspapers and functioned as a means of constructing the social identity of the country's citizens. The most popular among them were nouns worker and collective farmer that indicated "prestigious" social classes in the Soviet Union. Groups of specific working and agricultural professions names were very frequent in the press publications and diverse in constituent units, while names of professions requiring special education and high qualification were quite rare in the press. A group of nouns denoting best workers (innovator, leader, stakhanovets, etc.) is specific to the analyzed historical period. In the Soviet time media names of persons indicating their work activities included evaluative, ideological and status pragmatic connotations. In the overwhelming majority of articles, they expressed positive evaluation and emphasized high status of people engaged in hard physical labor as well as their social significance in the society. The paper reveals that the leading type of identity in the press of the Soviet period was labor identity, and names of persons denoting their involvement in labor activity functioned in the press as key-
\end{abstract}

(C) Биюмена А. А., 2021

Контент доступен под лицензией Creative Commons Attribution 4.0 License.

The content is available under Creative Commons Attribution 4.0 License. 
words of the era, its lexical markers, ideological clichés and value dominants. They performed the following major functions: stimulated group solidarity, raised the value of the "man of labor" in the public consciousness, mobilized citizens for selfless labor and overfulfillment of norms and tasks.

Key words: media discourse, press, identity, labor, ideology, noun, nomination, evaluation, connotation.

\section{Введение}

Средства массовой коммуникации являются ключевой силой, формирующей ценностную модель того или иного общества, представляющую собой уникальную комбинацию признаков, которые присущи лишь определенному месту и времени [1]. Как любой классический идеологический миф, предполагающий моделирование совершенной реальности в исторической действительности, советский миф описывал светлое будущее, связанное с деятельностью власти (социализм/коммунизм), подготовкой к которому надлежало выступать настоящему [2, с. 151-152]. По словам Н. Е. Киселевой, в советском политическом дискурсе был создан специфический симулякр, в котором с помощью слов «большевики актуализировали столь свойственную русскому национальному характеру мифологему “обретения рая на земле”» [3, c. 8].

После революции 1917 г. в стране провозглашается дестратификация общества, т. е. лишение всех слоев классообразующих черт и признаков [4, с. 22], и постулируется диктатура пролетариата. В советской прессе формируется специфический идеологический конструкт с мифологизированным содержанием рабочий класс, который трактовался как символ социалистического строя, «класс-мессия, ведущий социальный субъект мирового прогресса, основной субъект коммунистической партии, призванный быть социальным доказательством неуклонного движения к коммунизму» [5, с. 49]. Крестьяне рассматривались в советской мифологии как союзники рабочих в построении нового коммунистического общества. В советской идеологии общеупотребительным было клише «советский человек», в качестве одной из важнейших почетных обязанностей которого постулировался труд на благо Родины: «в новой социалистической догматике труд - естественное состояние свободной творческой натуры, которым и является советский человек» [3, с. 20].

Важнейшую роль в развитии общества играет коллективная идентичность его членов как «комплекс представлений, на которых выстраивается согласованная мотивация индивидуального и группового поведения» [6, с. 6]. Поскольку человек одновременно выполняет множество социальных ролей и включается в разнообразные типы социальных отношений, принято выделять разные типы идентичности - этническую, гражданскую, культурную, религиозную, профессиональную, гендерную и др. В структуре социальной идентичности советских людей, формируемой средствами массовой коммуникации, на первый план выдвигалась профессиональная идентичность как чувство принадлежности к определенному классу или профессиональному сообществу, понимание своей профессии и умение выполнять профессиональные обязанности [7].

Средством актуализации профессиональной идентичности в советской прессе выступали многочисленные статьи на трудовую тематику, в которых часто употреблялись имена существительные - наименования лиц по роду деятельности и профессии. Эти лексемы носят синкретичный характер, поскольку эксплицируют личностный и профессиональный компонент идентичности, называя одновременно личность и представителя определенной профессии $[8$, c. 18$]$.

Центральным понятием языковой картины мира является человек, поэтому наименования лиц как «ценностно значимая совокупность представлений о языковой личности, исторически сложившаяся в рамках национальной культуры как результат обобщения различных аспектов ценностных ориентаций - морально-этических, эстетических, прагматических установок и норм» [9, с. 5] занимают весьма значимое место в системе языка, а наиболее ярко национально-культурную специфику представления образа человека в том или ином социуме в конкретный исторический период можно обнаружить в номинациях, функционирующих в средствах массовой коммуникации. По мнению многих исследователей, решающая роль как в обновлении наименований лиц по профессии и роду деятельности, так и в выдвижении тех или иных номинаций на позицию центральных и наиболее частотных отводится экстралингвистическим факторам - развитию технического прогресса и росту определенных отраслей производства, общественному разделению труда и социальным изменениям $[8$, с. $5 ; 10$, с. $13 ; 11$, с. $7 ; 12$, с. 392].

С. И. Гарагуля пишет, что любое имя является свернутым лингвокультурным текстом [13, с. 5], а M. А. Лаппо предлагает считать таковым не только антропоним, т. е. личное имя или этноним, но «любую номинацию человека/группы/категории (профессионим, гендероним, религионим, другие соционимы)» и подчеркивает, что разнообразные прагматические коннотации номинативов могут быть актуализированы в реальном дискурсе [14, с. 38]. Поскольку образ человека представляет собой важнейший фрагмент 
языковой картины мира, актуальные в тот или иной исторический период названия профессий наряду с иными наименованиями человека несут в себе культурно значимые смыслы и создают знаковый образ своей эпохи.

\section{Материалы и методы}

Цель данной работы заключается в определении популярных в прессе советского времени наименований лиц, относящихся к их трудовой деятельности, и выявлении прагматических коннотаций данных единиц в медиадискурсе. Материал исследования составили 220 номинаций, представленных 1600 словоупотреблениями в статьях на трудовую тематику, опубликованных в центральных белорусских газетах «Советская Белоруссия» (СБ) и «Звязда» (Зв) в 1930-1980-е гг. Использовались методы контент-анализа, контекстуального и дискурсивного анализа.

\section{Результаты исследования}

В ходе проведенного анализа были выделены группы наименований лиц по вовлеченности в трудовую деятельность, характерные для прессы советского периода. Результаты проведенного исследования представлены в таблице.

Участие в трудовой деятельности, сфера занятости. Как видно из приведенной таблицы, более четверти употреблений лексем-наименований лиц по вовлеченности в трудовую деятельность (26,5%) приходится на представленную всего десятью единицами группу номинаций, в которую мы включили слова, обозначающие человека, занимающегося трудовой деятельностью, либо в наиболее общем виде указывающие на сферу занятости субъекта: рабочий, колхозник, колхозница, работник, работница, трудяшчийся, труженик, специалист, служащчии, инженер- но-технический работник. Эти единицы представляют собой гиперонимы по отношению к наименованиям конкретных профессий и специальностей.

Самые частотные лексемы не только в данной группе, но и во всем материале исследования - слово рабочий, которое встречается в проанализированных публикациях 133 раза (8,3 \% от всех анализируемых словоупотреблений), и колхозник/колхозница (суммарно 149 употреблений, или 9,3\%): Среди колхозников развернулось сочииалистическое соревнование за лучшее проведение весеннего сева, за высокий, сталинский урожай (СБ, 14.04.39); Вдохновенно трудился в этот день старейший рабочий завода В. Н. Шентарович (СБ, 16.10.83). Если в 1930-1940-е гг. в прессе несколько чаще встречается лексема колхозник, то в 1970-1980-е гг. в газетах превалирует слово рабочий, что, вероятно, можно объяснить развитием промышленности и строительством новых предприятий в стране, а также постепенным снижением количества лиц, занятых в сельском хозяйстве.

Частотны в проанализированных публикациях также существительные работник/работница, отмеченные в сумме 78 употреблениями (4,9 \%). Эти единицы используются журналистами как самостоятельно, так и в составных наименованиях в сочетании с существительным в форме родительного падежа (работница фабрики, работники станкостроительной отрасли и т. п.): Працаўнікі сельскай гаспадаркі Гомельскай вобласиі, спаборнічаючы за дастойную сустрэчу 50-годдзя ўтварэння СССР, выканалі план адгрузкі харчовай бульбы ў саюзны фонд (Зв, 18.10.72); Работники комбината постоянно интересуются спросом покупателей на те или иные изделия (СБ, 24.05.64).

Т а б ли ц а

Наименования лии по вовлеченности в трудовую деятельность в советской прессе

\begin{tabular}{|c|l|c|c|l|}
\hline № & \multicolumn{1}{|c|}{ Семантика } & $\begin{array}{c}\text { Кол-во } \\
\text { лексем }\end{array}$ & $\begin{array}{l}\text { Кол-во упот- } \\
\text { реблений, \% }\end{array}$ & \multicolumn{1}{|c|}{ Лексемы } \\
\hline 1 & $\begin{array}{l}\text { Участие в трудовой деятель- } \\
\text { ности, сфера занятости }\end{array}$ & 10 & 26,5 & $\begin{array}{l}\text { Рабочий, колхозник, колхозница, работница, трудящийся, } \\
\text { труженик, специалист, служащий }\end{array}$ \\
\hline 2 & Рабочие профессии & 94 & 21 & Плотник, токарь, строгаль, вязальщица, асфальтоукладчик \\
\hline 3 & Работники отрасли & 28 & 7 & Пищевик, станкостроитель, металлург, шинник, нефтяник \\
\hline 4 & $\begin{array}{l}\text { Сельскохозяйственные } \\
\text { специальности }\end{array}$ & 31 & 15,5 & $\begin{array}{l}\text { Тракторист, картофелевод, хлебороб, телятница, пастух, } \\
\text { доярка, животновод }\end{array}$ \\
\hline 5 & Лучшие работники & 17 & 9 & $\begin{array}{l}\text { Передовик, ударник, стахановец, рационализатор, новатор } \\
\text { Бригадир, директор, председатель, начальник, министр, } \\
\text { командир }\end{array}$ \\
\hline 7 & $\begin{array}{l}\text { Должности } \\
\text { Высококвалифицированные } \\
\text { работники }\end{array}$ & 25 & 5 & $\begin{array}{l}\text { Инженер, учитель, ученый, экономист, технолог, } \\
\text { композитор }\end{array}$ \\
\hline Корпоративные номинации & 8 & 1 & Кировец, сельмашевец, рассветовец, мотовелозаводец \\
\hline
\end{tabular}


В пятидесятые годы данная группа пополняется наименованием трудящиеся, а в семидесятые - существительным труженики: В начале текущего года трудящиеся Гродно и Лиды начали соревноваться между собой за достойную встречу 40-летия БССР (СБ, 27.07.58). Последняя единица нередко встречается в прессе в составе клишированных сочетаний сельские труженики и труженики села: Верность идеалам зачинателей этого почина продемонстрировали 15 октября на свочх рабочих местах тысячи производственников, тружсеников села, представителей интеллигенции (СБ, 16.10.83).

Невысокой частотностью в проанализированных текстах характеризуются лексемы специиалист, служащзий и сочетание инженерно-технический работник (суммарное количество употреблений - 2,2 \%), которые в контексте газетных статей в подавляющем большинстве случаев используются как члены перечислений, в которых обычно присутствует слово рабочий: Рыхтуючы дастойную сустрэчу 50-годдзю утвварэння СССР, рабочыя $\boldsymbol{i}$ служачыя Брэсикага дыванова-суконнага аб'яднання абавязаліся выпусціичь на сотні тысяч рублёу звышпланавай прадукцыл (Зв, 13.07.72).

Рабочие профессии. Группа названий рабочих профессий и специализаций наиболее разнообразна и многочисленна в проанализированных статьях - она включает в себя 94 единицы. При этом она является второй по частотности, составляя $21 \%$ от всех исследуемых словоупотреблений. Входящие в данную группу лексемы позволяют получить представление об уровне развития индустрии и приоритетных направлениях экономики СССР в разные десятилетия.

В 1930-е гг. большинство встречающихся в белорусской прессе названий рабочих специальностей относятся к ремеслам, которые состоят «в обрабатывающих действиях над каким-либо уже добытым природным материалом (“веществом”, “массой”) с целью получения из него конечного продукта в виде, главным образом, “вещи” непосредственно бытового назначения» [15, с. 339] (кожевник, резчик, столяр, токарь, строгальщчик, шлифовщчик, каменщик): Не отстают от каменщиков и плотники (СБ, 21.06.39); Слесарь механосборочного ичеха тов. Харламов выполняет норму на 400 процентов (СБ, 09.12.37).

В военные и послевоенные 1940-е гг. большое внимание в средствах массовой коммуникации уделяется металлургической промышленности, производству оружия и транспортной отрасли, поэтому на первый план выходят такие номинации профессий, как мартеновец, сталеплавильщик, сталевар, доменшуик, машинист, кочегар: Калектыу дэпо абавязаўся... абучыцьь 20 машыністаў, 25 памочнікаў машыністаў, 50 качагараў (Зв, 24.09.44); Мартэнай- цы і пракатчыкі металургічнага завода імені Сталіна па-франтавому змагающица за выкананне $і$ перавыкананне заказаў на спецыылльную высокаякасную сталь для абароннай прамысловасиі (СБ, 28.10.42).

В пятидесятые годы, в ходе восстановления разрушенной войной страны, популярными в прессе становятся названия различных строительных профессий и специализаций (слесарь, наладчик, экскаваторщик, карьерщчк, гранитчик): Высокопроизводительно трудятся в эти дни экскаваторщик Петр Мицкевич, мотовозчик Григорий Пинчук, съемщица Анастасия Туровеи, заливщица Вера Журавская и многие другие (СБ, 30.07.58).

В 1960-1980-е наблюдается бурное развитие легкой и нефтехимической промышленности, поэтому газеты часто публикуют статьи о вязальщицах, ленточницах, вышивальщицах, прядильщицах, мотальщицах, швеях-мотористках, а также о бурильщиках и взрывниках: Так работают прядильщица E. Прокопенко, ткачиха Т. Лучина, ленточница B. Касперович и тысячи других работниц (СБ, 24.05.64); Тут умела арганізавана праца, высокая дысчиыпліна, кожны член брыгады валодае сумежнымі спецььяльнасияяі - бурыльшчыка, узрыуйніка $i$ машыніста самаходнага вагона (Зв, 18.10.72).

Работники отрасли. Тесную связь с экстралингвистическими факторами обнаруживают также наименования работников тех или иных отраслей, составляющие 7 \% словоупотреблений в материале исследования. Так, в тридцатые годы наиболее частотными среди них были железнодорожник и торфяник, в сороковые - оружейник, транспортник, железнодорожник, металлург, в послевоенные годы - химик, мелиоратор, машиностроитель, железнодорожник, нефтяник, нефтепереработчик, строитель: Бригада знатного торфяника Федоса Ефремовича Зубова на 44 дня раньше срока выполнила сезонное задание по добыче торфа (СБ, 21.06.39); У адказ на заклік металургаў рабочыя значнаўзнялі прадукијьйнасцьь працьы (Зв, 25.11.44); Перад будаўнікамі 200-кватэрнага дома пастаўлена сёлета задача асвоіи̧ь 2.900 тысяч рублёу (Зв, 29.04.53); Цяпер меліяратары рыхтуюиь для гэтых гаспадарак новыя тарфяныя масівы плошчай больш як 700 гектараў (Зв, 29.06.66); Замечательную трудовую победу одержали на предмайской вахте химики Бобруйского гидролизного завода (СБ, 31.03.64); Шахтеры и железнодорожники, сталевары и строители, нефтяники и лесники сообщают о своих трудовых победах в честь праздника 1 Мая (СБ, 17.04.64); Нефтепереработчики и химики Новополочка широко развернули сочииалистическое соревнование за увеличение выпуска, улучшение качества товаров народного потребления (СБ, 07.10.83). 
Сельскохозяйственные специализации. Группа наименований работников сельского хозяйства представлена в материале исследования 31 единицей, доля употреблений которых составляет 15,5%. Данная группа включает в себя гиперонимы земледелеи, хлебороб, животновод, а также единицы-гипонимы, называющие конкретные специализации сельских работников (механизатор, тракторист, овощзевод, льновод, картофелевод, кукурузовод, жнея, доярка, свинарка, телятница, пастух, скотник): Это убедительно доказывают жнивотноводы Шарковщинского района, где в нынешний стойловый период производство молока уже поднялось на 20 процентов к прошлогоднему уровню (СБ, 23.11.83); Телятница Пелагея Рачкевич обеспечила хороший уход за молодняком (СБ, 22.06.39); Трактарыст Канстаниін Стойлік разам са сваім напарнікам Міхаілам Палуйчыкам закончыу баранаванне пасеваў бульбы (Зв, 14.06.66); Па-гаспадарску клапочящуца пра «беларускі шоўк» ільнаводы калгаса «Сияг камуны» (Зв, 15.08.72).

Лучшие работники. Представляется целесообразным включить в корпус наименований лиц по вовлеченности в трудовую деятельность группу слов, обозначающих лучших работников, поскольку в советском государстве трудовые успехи считались важнейшим показателем социальной идентичности личности, а также ввиду распространенности данных номинаций в средствах массовой коммуникации. Указанная группа, включающая в себя лишь 9 единиц, составляет $15 \%$ всех словоупотреблений в материале исследования.

Можно говорить об определенной «моде» на ту или иную номинацию в разные годы. Например, самая частотная лексическая единица этой группы cmaxaновеи (134 употребления) встречается в газетных публикациях 98 раз в 1930-е гг., 29 раз в 1940-е гг. и 7 раз в 1950-е гг., а в последующие десятилетия выходит из употребления: За это время выросло количество стахановцев, которых в артели сейчас насчитывается 127 человек (СБ, 27.05.39).

Четыре лексемы (передовик, ударник, новатор, рациионализатор) представлены в прессе во все анализируемые периоды: Немало талантливых изобретателей, рационализаторов, смельх новаторов производства работают в любой отрасли промыиленности и сельского хозяйства нашей республики (СБ, 11.05.39); Лучшим наладчиком автоматов является комсомолец рационализатор Алексей Туманов (СБ, 30.07.58); Ужо вызначаліся перадавікі - вадзіцелі Кавалёу і Емельянаў (Зв, 18.02.66); Каждый третий работающий на предприятии - ударник коммунистического труда (СБ, 16.10.83).

Характерным для 1930-1950-х гг. является использование существительного изобретатель, а в 1980-е в фокус внимания прессы выдвигается слово многостаночник: В основе успеха - движение многостаночников, овладение передовыми приемами труда, техническое переоснащчение производства, творческий энтузиазм работников (СБ, 14.12.83).

Должности. Наименования лиц по занимаемой должности составляют 9 \% словоупотреблений в материале исследования. Они включают в себя как обозначающие руководящих работников существительные широкой семантики, которые требуют уточнения в виде существительного в форме родительного падежа (директор, председатель, руководитель, начальник, министр, командир), так и более конкретные номинации, относящиеся к руководителям небольших рабочих коллективов (звеньевая, бригадир, прораб): С большой речью на пленуме выступил секретарь ЦК КПСС П. Н. Демичев... (СБ, 16.01.64); Многие выступающие, в частности председатель сельхозартели "XVIII партсъезд» т. Федорович, говорили о том, что лен и кукуруза являются важнейшими источниками развития и других отраслей общественного хозяйства (СБ, 29.07.58); Три года работает бригадиром огородной бригады коммунист тов. Пилипенко (СБ, 11.05.39); Гэтымі днямі раённы сельскагаспадарчы аддзел правёу аднадзённы семінар звеннявых па выроччванню ільну (Зв, 21.03.53).

Высококвалифицированные работники. Названия представителей профессий, требующих специального образования и высокой квалификации, составляют лишь 5 \% всех словоупотреблений в проанализированных текстах. Среди них встречаются имена творческих (художник, композитор), научно-педагогических (учитель, преподаватель, ученый), инженерно-технических (инженер, конструктор, технолог) и других профессий: Многія маладыя вучоныя Беларускага політэхнічнага інстытута, якія маюиь званне кандыдата навук, рыхтуюичза да паступлення ў дактарантуру (Зв, 14.06.53); По предложению группы инженеров С. С. Шпилевского, 3. Н. Дайнеко, А. М. Ярощенко внедрен умягченный режим гидролиза (СБ, 31.03.64).

Корпоративные номинации. Организационная идентичность, т. е. осознание себя как члена трудового коллектива и формирование чувства принадлежности к организации, является важным компонентом социальной самоидентификации индивидуума и понимания им своего места в мире [16, с. 400]. В проанализированных материалах советской прессы зафиксировано 8 лексических единиц, называющих человека как члена определенной организации (кировец, димитровеи, сельмашевец, рассветовец, автозаводеи, радиозаводеи, мотовелозаводец, тракторозаводеи): С большим вниманием прослушали кировцы обращчение московских рабочих (СБ, 01.04.39); Сель- 
машауццы поўныя рашучасияі за кошт сэканомленага металу выпусиіизь у 1966 годзе дадаткова да плана некалькі дзесяткаў трактарных прычэпаў $і$ камбайнаў (Зв, 08.01.66); Уверенный старт тракторозаводцев (СБ, 03.01.74); Мотовелозаводцы, как и все советские люди, вносят свой посильный вклад в выполнение Продовольственной программы СССР (СБ, 04.12.83).

Прагматические коннотации. В контексте советской прессы наименования лиц по профессии и вовлеченности в трудовую деятельность реализовывали разнообразные прагматические коннотации, в первую очередь, оценочные, статусные и идеологические.

Как видно из большинства приведенных выше контекстов, анализируемые номинации актуализируют в газетных статьях преимущественно положительную оценочность, поскольку они обычно используются в материалах, повествующих о трудовых подвигах, обязательствах и починах, перевыполнении норм и планов, трудовом энтузиазме и победах в социалистическом соревновании. Об этом свидетельствует и наличие в материале исследования отдельной группы наименований, указывающих на людей, отлично выполняющих свою работу (передовики, ударники, стахановцы), удельный вес которых составил 15 \% всех анализируемых употреблений.

Номинация часто рассматривается как оценка, которая соотносится с системой заложенных в обществе ценностей [9, с. 11], соответственно, реализуемая в прессе социальная оценочность указывает также на высокий статус рабочих и сельскохозяйственных специальностей в советском обществе. В корпусе проанализированных текстов суммарное употребление лексем, обозначающих рабочих и колхозников (гипонимы и гиперонимы), составляет более шестидесяти процентов, в то время как наименования профессий, требующих специального образования и высокой квалификации, составляют лишь 5 \% всех словоупотреблений в материале исследования. Кроме того, обращает на себя внимание дробность членения семантических полей «рабочие» (94 единицы) и «колхозники» (31 единица), что также указывает на высокую значимость данных профессий в пространстве советской идеологии.

Идеологические коннотации анализируемых номинаций заключаются, в первую очередь, в восхвалении людей, занимающихся тяжелым физическим трудом, акцентировании их ведущей роли в создании и развитии советского общества и государства. По мнению исследователей, стереотип «человек труда» является идеологическим маркером советской эпохи $[17$, с. 149].

\section{Заключение}

Проведенный анализ позволяет сделать вывод о том, что наименования людей по профессии и вовле- ченности в трудовую деятельность (особенно гиперонимы рабочий и колхозник) выступали в советской прессе в роли идеологических клише, своеобразных лексических маркеров и ценностных доминант эпохи, обладающих высоким прагматическим потенциалом. Данные лексемы использовались в медиадискурсе в роли ключевых слов эпохи, характерными признаками которых являются: соотнесенность с определенным историческим периодом; номинация актуальных понятий и явлений эпохи, находящихся в центре общественной дискуссии; высокая частотность употребления как в заголовочной позиции, так и в текстовом пространстве статьи [18, с. 7]. Ключевые слова эпохи, с одной стороны, определенным образом запечатлевают исторический период, а с другой стороны, используются как средство конструирования особой картины эпохи и манипулирования массовым сознанием.

Поскольку образ человека является важнейшим фрагментом языковой картины мира, использование в пространстве медиадискурса тех или иных номинаций лиц способствует формированию культурного самосознания народа [9, с. 11] и конструированию его социальной идентичности. Именно профессиональная идентичность была превалирующим типом как социальной, так и личностной идентичности в советских медиа. В проанализированных материалах присутствуют также маркеры гражданской (coвеmский человек) и политической идентичности (коммунист, комсомолеч), в то время как семейно-ролевые, этнические, культурные, религиозные обозначения человека встречаются крайне редко или отсутствуют.

Подобное использование номинаций людей по профессии и вовлеченности в трудовую деятельность было нацелено на то, чтобы стимулировать групповую сплоченность советских людей, повышать в общественном сознании ценность принадлежности к категории «людей труда» и мобилизовывать граждан на выполнение желательных для общества действий, т. е. на самоотверженный труд и перевыполнение норм и заданий.

\section{ЛИТЕРАТУРА}

1. Леви-Строс К. Структурная антропология / пер. с фр. Вяч. Вс. Иванова. М. : ЭКСМО-Пресс, 2001. 512 с.

2. Докучаев И. И. Ценность и экзистенция : основоположения исторической аксиологии культуры. СПб. : Наука, Санкт-Петербургская издательская фирма, 2009. $594 \mathrm{c}$.

3. Киселева Н. Е. Трансформация лексики советского человека: культурологический анализ : автореф. дис. ... канд. культурологии. М. : Мос. гос. ун-т культуры и искусств, 2008. 25 с.

4. Савельев С. И. Социальная политика советского государства в деревне 1917 г. - начала 1930-х гг. (на ма- 
териалах Нижнего Поволжья) : автореф. дис. ... д-ра ист. наук. Саратов : Сарат. гос. агр. ун-т, 2005. 35 с.

5. Барулин В. С. Российский человек в XX веке. Потеря и обретение себя. СПб. : Алтейя, 2000. 431 с.

6. Семененко И. С. Политическая идентичность в контексте политики идентичности // Политическая экспертиза : политэкс. 2011. Т. 7, № 2. С. 5-24.

7. Шнейдер Л. Б. Профессиональная идентичность. M. : MOCУ, 2001. $272 \mathrm{c}$.

8. Соловьева М. А. Имена существительные - номинации лиц по профессии и роду занятий в русском языке XXI века : автореф. дис. ... канд. филол. наук. В. Новгород : Владимир. гос. ун-т им. А. Г. и Н. Г. Столетовых, 2018. 22 с.

9. Катермина В. В. Национально-культурная специфика образа человека : автореф. дис. ... д-ра филол. наук. Волгоград : Кубан. гос. ун-т, 2005. 39 с.

10. Зарипова B. М. Номинация лиц в языке газеты : эволюция этикетных тенденций. Самара : Изд-во СГАУ, 2016. $180 \mathrm{c}$.

11. Новикова Е. Ю. Структура, семантика и тенденции развития наименований лиц по профессии в современном немецком языке : автореф. дис. ... канд. филол. наук. М. : Мос. гос. лингв. ун-т, 2006. 25 с.

12. Фатеева И. М. Наименования профессий как социолингвистический фактор пополнения отраслевой терминосистемы // Филологические науки. Вопросы теории и практики. 2018. № 9 (87), ч. 2. С. 392-396.

13. Гарагуля С. И. Антропонимическая прагматика и идентичность индивида : автореф. дис. ... д-ра филол. наук. М. : МГУ им. М. В. Ломоносова, 2009. 42 с.

14. Лаппо М. А. Прагматический потенциал лексем, обозначающих лиц по роду занятий : динамический аспект (на примере лексемы «учитель») // Вестник Том. гос. ун-та. Филология. 2014. № 2 (28). С. 37-49.

15. Степанов Ю. С. Константы : словарь русской культуры. 2-е изд., испр. и доп. М. : Академ. проект, $2001.990 \mathrm{c}$

16. Тренева Т. В. Корпоративная идентичность работника как составляющая его социальной идентичности // Преподаватель ХХІ века. 2012. № 1-2. С. 400-404.

17. Юсупова А. М. Стереотип «человек труда» в региональном публицистическом дискурсе // Вестник Челяб. гос. ун-та. 2014. № 26 (355). С. 148-151.

18. Шачкова И. Ю. Семантика «ключевых слов эпохи» (эпоха Т. Блэра, 1997-2007) : автореф. дис. ... канд. филол. наук. Н. Новгород : Нижегор. гос. лингв. ун-т им. Н. А. Добролюбова, 2008. 18 с.

\section{REFERENCES}

1. Levi-Stros K. Strukturnaya antropologiya [Structural anthropology]. Moscow: EKSMO-Press, 2001. 512 p.

2. Dokuchaev I. I. Cennost' $i$ ekzistenciya: osnovopolozheniya istoricheskoj aksiologii kultury [Value and Existence: Foundations of the Historical Axiology of Culture]. Saint Petersburg: Nauka, 2009. 594 p.
3. Kiseleva N. E. Transformaciya leksiki sovetskogo cheloveka: kul'turologicheskij analiz [Transformation of the vocabulary of the Soviet people: a cultural analysis]. PhD Dissertation Abstract. Moscow: Moscow State Art and Culture University, 2008. 25 p.

4. Savel'ev S. I. Social'naya politika sovetskogo gosudarstva v derevne 1917 g. - nachala 1930-h gg. (na materialah Nizhnego Povolzh'ya) [Social policy of the Soviet state in the countryside 1917 - early 1930s (based on materials from the Lower Volga region)]. Doctor of History Dissertation Abstract. Saratov: Saratov State Agricultural University, 2005. $35 \mathrm{p}$.

5. Barulin V. S. Rossijskij chelovek v XX veke. Poterya $i$ obretenie sebya [Russian people in the twentieth century. Losing and finding yourself]. Saint Petersburg: Altejya, 2000. $431 \mathrm{p}$.

6. Semenenko I. S. Politicheskaya identichnost'v kontekste politiki identichnosti [Political identity in the context of identity politics]. In: Politicheskaya ekspertiza: politeks. 2011. V. 7. No. 2. Pp. 5-24.

7. Shnejder L. B. Professional'naya identichnost' [Professional identity]. Moscow: MOSU, 2001. 272 p.

8. Solov'eva M. A. Imena sushchestvitel'nye - nominacii lic po professii i rodu zanyatij v russkom yazyke XXI veka [Nouns - nominations of persons by profession and occupation in the Russian language of the XXI century]. PhD Dissertation Abstract. Velikiy Novgorod: Vladimir State University, 2018. 22 p.

9. Katermina V. V. Nacional'no-kul'turnaya specifika obraza cheloveka [National and cultural specificity of the human image]. Doctor of Philology Dissertation Abstract. Volgograd: Cuban State University, 2005. 39 p.

10. Zaripova V. M. Nominaciya lic v yazyke gazety: evolyuciya etiketnyh tendencij [Nomination of persons in the language of the newspaper: the evolution of etiquette trends]. Samara: SGAU Publ., 2016. 180 p.

11. Novikova E. Yu. Struktura, semantika i tendencii razvitiya naimenovanij lic po professii $\mathrm{v}$ sovremennom nemeckom yazyke [Structure, semantics and development trends of names of persons by profession in modern German]. PhD Dissertation Abstract. Moscow: Moscow State Linguistic University, 2006. 25 p.

12. Fateeva I. M. Naimenovaniya professij kak sociolingvisticheskij faktor popolneniya otraslevoj terminosistemy [Names of professions as a sociolinguistic factor in replenishing the sectoral terminology system]. In: Filologicheskie nauki. Voprosy teorii i praktiki. 2018. No. 9(87). Part 2. Pp. 392-396.

13. Garagulya S. I. Antroponimicheskaya pragmatika i identichnost' individa [Anthroponymic pragmatics and individual identity]. Doctor of Philology Dissertation Abstract. Moscow: Moscow State University, 2009. 42 p.

14. Lappo M. A. Pragmaticheskij potencial leksem, oboznachayushchih lic po rodu zanyatij: dinamicheskij aspekt (na primere leksemy "uchitel"”) [Pragmatic potential of lexemes denoting persons by occupation: dynamic aspect (on 
the example of the lexeme "teacher")]. In: Bulletin of Tomsk State University. Philology. 2014. No. 2 (28). Pp. 37-49.

15. Stepanov Yu. S. Konstanty: Slovar'russkoj kul 'tury [Constants: Dictionary of Russian Culture]. $2^{\text {nd }}$ ed. Moscow: Akadem. proekt, 2001. 990 p.

16. Treneva T. V. Korporativnaya identichnost' rabotnika kak sostavlyayushchaya ego social'noj identichnosti [Employee's corporate identity as a component of their social identity]. In Prepodavatel'XXI veka. 2012. No. 1-2. Pp. 400-404.

Минский государственный лингвистический универcumem

Биюмена А. А., кандидат филологических наук, доиент, докторант кафедры речеведения и теории коммуникации

E-mail:a-mesyats@tut.by

Тел.: (375)297619969

Поступила в редакциию 7 ноября 2020 г.

Принята к публикации 29 декабря 2020 г.

\section{Для цитирования:}

Биюмена А. А. Лексические доминанты как компоненты ценностной модели общества // Вестник Воронежского государственного университета. Серия: Лингвистика и межкультурная коммуникация. 2021. № 1. C. 6-13. DOI: https://doi.org/10.17308/lic.2021.1/3232
17. Shachkova I. Yu. Semantika "klyuchevyh slov epohi" (epoha T. Blera, 1997-2007) [Semantics of "key words of the era" (T. Blair era, 1997-2007)]. PhD Dissertation Abstract. Nizhny Novgorod: Nizhny Novgorod Linguistics University, 2008. $18 \mathrm{~s}$.

18. Yusupova A. M. Stereotip "chelovek truda" v regional'nom publicisticheskom diskurse [The stereotype "man of labor" in regional publicistic discourse]. In: Bulletin of Chelyabinsk State University. 2014. No. 26 (355). Pp. 148-151.

\section{Minsk State Linguistic University}

Biyumena A. A., Candidate of Philology, Associate Professor, Doctoral Student of Speech Studies and Theory of Communication Department

E-mail:a-mesyats@tut.by

Tel.: (375)297619969

Received: 7 November 2020

Accepted: 29 December 2020

\section{For citation:}

Biyumena A. A. Lexical dominants as components of the society value model. Proceedings of Voronezh State University. Series: Linguistics and Intercultural Communication. 2021. No. 1. Pp. 6-13. DOI: https://doi. org/10.17308/lic.2021.1/3232 